\title{
The Fluid and Transcultural Self: Renegotiating the East Asian Female Identity in The Clay Marble by Minfong Ho
}

\author{
SYAMSINA ZAHURIN SHAMSUDDIN \\ Department of English, \\ Faculty of Modern Languages and Communication, \\ Universiti Putra Malaysia \\ IDA BAIZURA BAHAR \\ Department of English, \\ Faculty of Modern Languages and Communication, \\ Universiti Putra Malaysia \\ idabb@upm.edu.my
}

\begin{abstract}
This paper examines how the contemporary Chinese-American author Minfong Ho (b. 1951) portrays Dara, the female protagonist of The Clay Marble (1991), in her practice of culture in Cambodian society in order to explore the Western perspective of the East Asian female identity as voiceless, submissive and hypersexual. Using the concepts of identity fluidity as proposed by the sociologist and cultural theorist Stuart Hall (2011) and his views on the decentring of the individual, the paper aims to investigate how the three concepts of the enlightenment subject, the sociological subject and the postmodern subject interact with Arianna Dagnino's (2015) concept of transculture/ality, or intermingling of cultures, in The Clay Marble through Dara's practice of culture in Cambodian society and how she is decentred as her identity evolves. Ho's portrayal of Dara reveals an East Asian female who experiences identity fluidity in her thinking, attitude and behaviour while her stable, regular and fixed self in the enlightenment subject phase becomes decentred through transculture/ality at the sociological subject phase. Here, through transculture/ality, or her interaction or communication within her culture, she links herself to society and transforms as she finds her voice and manifests individual agency. By doing so, Dara enters the third phase, the postmodern subject, where her thinking, attitude and behaviour are constantly changing as are the ways in which she is defined and addressed in her Cambodian culture.
\end{abstract}

Keywords: East Asian female identity; identity fluidity; Minfong Ho; The Clay Marble; transculture/ality

\section{INTRODUCTION}

This paper applies the concept of identity fluidity and transculture/ality to the portrayal of the female protagonist, Dara, in The Clay Marble (1991) by Minfong Ho by examining Dara's practice of culture in Cambodian society and how she is decentred vis-à-vis the Western view of the East Asian female identity as voiceless, submissive and hypersexual. Ho initially portrays Dara as immature, childish and naïve. She is viewed as unimportant by her brother and often ignored in terms of decision-makings and leadership in her family, and she is often left to spend time with her new friend, Jantu. We hypothesise, however, that, through Ho's depiction of Dara's cultural intermingling with Jantu, Dara progressively undergoes a transformation, becoming opinionated, finding her voice and displaying individual agency in her thinking, attitude and behaviour as she eventually assumes an identity that does not conform to the idealistic image of the traditional Cambodian woman. As Hall points out, identity arises through a lack of wholeness gained from our surroundings and by how we want others to see us rather than from the identity already inside us. For Hall, identity is always incomplete, "in process" and "being formed" (2011, p. 608). Hall thus dismisses the idea of identity as a finished product and argues instead that the person who previously experienced a united and stable identity has, as a result of being decentred, become fragmented, constituted 
not of a single but of many, often conflicting or unfinished, identities (2011, p. 598). Hall also posits five major theoretical moves of decentrings that individuals may experience at the second stage of identity fluidity, namely the sociological subject. This paper, via an examination of Ho's portrayal of Dara in her practice of culture in Cambodian society, thus also attempts to explore how the process of intermingling of cultures, or the concept of transculture/ality advanced by the transcultural scholar Arianna Dagnino, contributes to Dara's decentring at the sociological subject stage.

In particular, female issues have been the focus of many current studies in literary criticism: for example, the issue of engendered violence against women (Zabihzadeh et al. 2015, Chua et al. 2016, Dodhy et al. 2017, Salih et al. 2018), the dilemma regarding cultural, ethnic and religious identities (Al-Karawi \& Ida Baizura Bahar 2013, Nur Fatin Syuhada Ahmad Jafni \& Ida Baizura Bahar 2014, Al-Karawi \& Ida Baizura Bahar 2014, Farahanna Abd Razak et al. 2016, Almutairi et al. 2017, Ida Baizura Bahar 2019, Ida Baizura Bahar et al. 2019) and the prospect of outgrowing the sense of rootlessness in diasporic texts for immigrant female characters (Noraini Md. Yusof et al. 2012, Krishnamoorthy \& Krishnamurthy 2016). Others include the study of the body and female identity in the context of Irish culture (Chang 2017) and the modification of gender by power, which results in identity crisis among women (Moosaivinia \& Youseffi 2018). In the context of this study, these female characters have been portrayed as subject to the desires and needs of the men in their lives, and appear to surrender to their fates and comply with the cultural norms embedded in these societies. Pertinent questions therefore arise: are these female characters voiceless and submissive all along? Have they become hypersexual as they are expected to comply with their men's needs and desires?

\section{LITERATURE REVIEW}

\section{THE LIVED EXPERIENCE OF CAMBODIAN WOMEN}

As we focus more on Cambodian women living in traditional Cambodian society, it is important for us to highlight the lived experience of these women. In rural Cambodia, such as in the suburbs of Phnom Penh and Siem Reap, the womenfolk are bound to the Cambodian culture of staying at home with the expectation to care for the children, provide food for the family by tending the garden vegetables and rounding up the farm animals, and prepare food for the family. They are expected to follow this tradition and be submissive to their fate. In general, most Cambodian women believe they have no voice in obtaining a better future. They cannot explicitly express their struggles and problems to their families, societies or the government as it is very difficult to change the mindsets of the people in Cambodian society who conform to these traditional roles. As expected, most Khmer women are not well educated, having spent their youth working instead of learning skills or obtaining a proper education (Sheeley 2012, pg. 68).

A study by native Cambodian Rama Ariadi (2016), on two successful Cambodian women, provides a clear understanding of their challenges and triumphs in pursuing their aspirations in Cambodian society, which is still firmly rooted in Cambodian beliefs, values and traditions. Though Cambodia is now advancing to a more modern era and has made progress towards gender equality and women's empowerment, there are, however, many areas where women are still placed in secondary positions and expected to be submissive, voiceless and to focus more on their household duties. For example, Chantty, one of the women who is a successful singer, laments how she is bound to the Cambodian traditions that expect women to be demure, passive and submissive. As much as she wants to promote the songs from Cambodia's golden period to the world, her efforts are limited as she faces criticism from Cambodian society and her family on how she carries herself in public and how she must preserve her Cambodian identity. As the atmosphere of the patriarchal Cambodian society 
becomes more woman friendly, Chantty observes that opportunities now arise for women to change for the betterment of themselves and that women must be brave enough to seize these opportunities. Dina, another successful female artist and entrepreneur, also agrees with Chantty and believes that, through art, progressive changes can be implemented in Cambodian society, and that women should strive to be empowered and be at par with men. She also notes that, though women now have many opportunities to empower themselves, they are still seen as second-class citizens whose voices are often ignored and whose hard work is not recognised as they are expected to comply with Cambodian beliefs, values and traditions that a woman's role is confined to the threshold of her home (Rama Ariadi 2016).

Another study by another Cambodian scholar, LinDa Saphan (2016), examines two popular female icons in Cambodian music of the pre-war era who embody the identity of the modern Cambodian woman. In the context of the process to become a more modern Cambodia, women are excluded in the development of certain areas such as architecture, painting and literature, which have always been considered men's domain. The Cambodian social construct, however, allows them to play a role in music and cinema; thus, placing them as part of the elite class of women in Cambodia who have the privilege to express their voices. In 1960s Cambodia, for example, notable singers included both the more conservative Ros Serey Sothea, who revealed her modern way of thinking while preserving the identity of Khmer womanhood in her own way, as well as Pen Ran, who embodied a modern Cambodian woman who totally rejected the traditional Cambodian culture and its expectation that Cambodian women be obedient, voiceless and submissive.

A study by Cambodian scholar Thavry Thon (2017), a young Cambodian woman who attempts to seek changes for women in her country, highlights the strong influence and intensity of the Chbab Srey, the code of conduct for Cambodian women passed down from one generation to the next. Thavry concurs that most Cambodian women believe in and follow the practice of the Chbab Srey code of social conduct without objection, and accept its strict and rigid principles. The ideals of the Chbab Srey have been ingrained in the minds of Cambodian girls since birth and continue to strengthen throughout their daily lives. When they enter school, they are further instilled with the values and code of conduct of the proper woman who is pure, gracious, obedient and submissive, and they are expected to keep their thoughts and opinions to themselves.

\section{MINFONG HO AND THE CLAY MARBLE}

Within the context of the problem statement discussed above, writings about Asia by the contemporary Chinese-American writer Minfong Ho have been viewed as her attempts to address Western misinterpretations of East Asia and reveal insights of the East Asia that she knows. Ho's novels focus on young female protagonists who live in East Asia, struggling to overcome injustice and hurdles in life, and are based on events she experienced in Thailand and Cambodia (Wiggins 2006). Set in war-ravaged Cambodia after the fall of the communist Khmer Rouge regime (1975-1979), The Clay Marble, Ho's third novel, has received international recognition and awards such as first prize in the 1993 AsiaWeek Magazine Annual Short Story Contest and the Hungry Mind Reviews Children's Book of Distinction award in 1992. Used as a literature textbook for secondary students in Malaysia, the novel provides insight into the lives of other adolescents in other parts of East Asia that they can relate to. The students' connection to the text provides them indirect experiences, and encourages their critical and analytical skills (Chin 2019). The novel narrates the story of a twelve-year-old girl named Dara who escapes home with her mother and brother, Sarun, to Nong Chan, a refugee camp on the border of Cambodia and Thailand, where she meets a girl, Jantu, who is a year older than her. Having both lost their family members in the war after the 
collapse of the Khmer Rouge regime in the early 1980s, they develop a relationship over time with Jantu becoming somewhat of a mentor to Dara.

Though there have been noteworthy studies conducted on the works by Minfong Ho, most have focused primarily on her first novel, Sing to the Dawn (1975), and on its protagonist Dawan in particular. Thus far, however, there has been very limited academic scholarship on The Clay Marble with the exception of two notable studies. In the first study, Yudha Christiyanto and Evy Tri Widyahening (2012) identify the types of direct speech in the novel that exhibit exercising of power, influencing, advising, or warning by the speaker as a form of communication and focus more on other characters in the novel instead of the protagonist, Dara. Paying the protagonist Dara little attention in their analysis, they conclude that Jantu, one of the major female characters, possesses her own voice, is very self-confident, and shows maturity and wisdom at a young age.

In contrast, a study by Yuliana Tri Nirmayanti (2013) examines the novel as an example of work by a Chinese-American author offering a thorough depiction of gender role construction and its predisposition, where the patriarchal system in the narrative brings great suffering to the protagonist, and other male and female characters as well. More importantly, Dara, the protagonist, is described as resolving her conflicts, and finding the strength and perseverance to voice her mind as well as drawing support from other female characters in order to achieve her desires, wants and needs; by doing so, she liberates herself from patriarchy. The present paper therefore focuses more on Ho's portrayal of Dara as the protagonist of The Clay Marble as we explore the current Western understanding of the East Asian female identity perceived as voiceless, submissive and hypersexual by applying the concepts of identity fluidity and transculture/ality to our analyses of Dara's practice of culture in Cambodian society.

\section{METHODOLOGY AND CONCEPTUAL FRAMEWORKS}

This study focuses on a 1991 novel by Minfong Ho, The Clay Marble, which is set in Cambodia's post-Khmer Rouge era and tells the hardship of a young female protagonist, Dara, who faces many challenges from the effects of the war and struggles for the betterment of her and her family's lives. The novel is ideal for this study as it focuses on the portrayal of East Asian female characters by the author, an East Asian woman herself, who has expressed her intention to depict situations inspired by real life in Southeast Asia. This study aims to examine one of the many literary representations of women living in Southeast Asia in order to provide a detailed understanding of Cambodian women. We will use textual analysis to determine the ways in which identity fluidity through transculture/ality forms the identity of Dara, the protagonist. The concepts of identity fluidity, namely the enlightenment subject, the sociological subject and the postmodern subject, will be applied to the novel via our analyses of the protagonist's behaviour, attitudes, ways of thinking, speeches, emotions, opinions and judgements in relation to transculture/ality. In short, we aim to investigate how the three concepts of identity fluidity are reflected in Ho's portrayal of Dara's practice of culture in Cambodian society and how, as her identity evolves, she becomes decentred through transculture/ality.

\section{IDENTITY FLUIDITY AND TRANSCULTURE/ALITY}

Before proceeding to how identity fluidity forms and transforms the identity of Dara in her practice of culture in Cambodian society and how she is thus decentred through cultural intermingling, this paper first discusses the concepts of identity fluidity. Hall initiated his study on the concepts of identity fluidity in "The Question of Cultural Identity" (2011) where he conceptualises that the first stage of identity fluidity, or 'the enlightenment subject', is a concept 
of a person who is centred and balanced, "a unified individual" capable of thinking and making decisions accordingly, of being aware and responsive to his or her surroundings, and able to act accordingly. For Hall, the "inner core", the centre, or the essence of a "fully centred" individual that he terms as "identity", materialises when he or she is born and will develop with the self. Hall points out, however, that, fundamentally, this centre or essence of the individual will still remain the same throughout the individual's lifetime. Hall believes that the essence of a person will help form the self to be "fully centred" and capable of thinking, making decisions and acting appropriately. Viewing the enlightenment subject as "individualist", independent and self-reliant, Hall adds that, with awareness of their actions, individuals strengthen their "inner core" and continue to develop their identity throughout their life (597).

Hall, however, also argues that this stable, unified and balanced individual will be decentred as the individual connects to society at the second stage of the self, known as 'the sociological subject', through the individual's association with "significant others, or people who interact and impose on the individual the values, meanings and symbols" (597). In short, the identity of an individual will form and transform as the individual mingles, interacts, and is influenced by other people and the culture of the world that the individual lives in. This classic sociological conception affirms that, through the "interaction" between the self and society, identity is created. In this sociological concept, identity will link the "inside" with the "outside" or the person with his or her society. It is important to highlight at this point of discussion that this study hypothesises that, in Ho's portrayal, Dara, at this second stage of identity fluidity, that of the sociological subject, is also undergoing the decentred process through intermingling of cultures, or transculture/ality. Transculture/ality, here, is a necessary concept, which we will discuss in detail later, to help explain the process in which she is being decentred.

In his research, Hall explores significant decentrings through which conceptual changes occur as he explains how the individual at the stage of the enlightenment subject with a fixed and stable identity is decentred into an open, contradictory, incomplete and fragmented identity which he terms as 'the postmodern subject'. Hall suggests that, constructed through the unconscious processes that the individual experiences over time, identity could not be established as innate in consciousness at birth. Viewing its unity as "imaginary" or "fantasised", Hall observes that identity is always incomplete, always "in process" and always "being formed" (Hall 608). Identity, according to Hall, arises through the lack of wholeness, which we gain from our surroundings, and by how we want others to see us and not so much from the identity already inside us.

Finally, Hall argues that the condition, when we put our own sociological selves into our cultural identities, and accept their meanings and values as "part of us", has helped to "align our subjective feelings with the objective places we occupy in the social and cultural worlds" (598). Hall thus suggests that identity connects the person with society and, at the same time, stabilises the person and his or her cultural world as he or she becomes "more unified and predictable". Then again, in modern societies, the person who has achieved a unified and stable identity is now said to be fragmented and to possess many contradictory or unresolved identities. Similarly, as a result of structural and institutional changes, the identities that shape the social landscapes and the identities that guarantee the subjective conformity of the objective "needs" of the culture are breaking up. The process of identification then, as we put our own selves into our cultural identities, becomes more "open-ended, variable and problematic" (598).

As the process of identification becomes more flexible, fluid and difficult, the final identity, 'the postmodern subject', materialises. This last concept of identity fluidity identified by Hall is theorised as having no static, vital or lasting identity due to the ways we are either represented or addressed within the cultural system that surrounds us. Identity, then, is shaped and modified continuously or viewed as a "moveable feast". Consequently, Hall concludes that 
the "fully unified, completed, secure and coherent identity" is just a dream for us to achieve. Rather, as the structures of meaning and the representations of culture develop, we are faced with a puzzling, momentary development of possible identities that we can relate to albeit temporarily (598).

Thus, to examine how Dara, at the second stage of the sociological subject phase, is decentred, we also apply the concept of transculture/ality as outlined by transcultural scholar Dagnino in her study, Transcultural Writers and Novels in the Age of Global Mobility (2015). Dagnino conceived the term 'transculture/ality' to be utilised within a literary framework as an approach to the study of the development of individual identity in order to critically analyse the relationship between cultures or within cultures. More importantly, transculture/ality explores the different modes of modernity and post-modernity as well as the outcome of the globalising imagination and its sense of belonging. Dagnino encapsulates the tenets of transculture/ality as a new conceptual paradigm and as a tool for cultural investigations, one that supports the idea of a transcultural approach that calls for the freedom of individuals to make their own cultural choices in order to acknowledge the production of plural identities and citizenships, as well as links to multiple communities and nationalities that form the lives of many individuals. It also denotes a distinguished paradigm of cultural development. Transculture thus represents a multidimensional space that gradually enables societies to connect and communicate throughout history, resulting in a state of accepting each other's cultures.

According to Dagnino, one of the key aspects of transculture/ality is its definition of culture as non-static, complex, dynamic and fluid, allowing individuals to make their own cultural choices. In essence, as culture is developed by interactions and infusions of communication between or among cultures, individuals have the right to make their own cultural decisions, act independently, make connections and create a multi-layered identity. More specifically, the mechanism of transculturation is defined by Dagnino as "selfculturation" with no particular pattern of transcultural change depending on the capacity of individuals to cope with diverse cultural identities based on their abilities, attitudes and experiences. Culture and the development of one's cultural identity are discovered as a dynamic process, one that does not deny the fundamental culture or nationality of a person but dismisses the notion of "fixed, self-enclosed, cultural, ethnic, and national identities or allegiances" (Dagnino 2015, p. 140).

\section{DISCUSSION}

\section{THE FLUID AND TRANSCULTURAL SELF OF DARA}

In her study on female icons in Cambodia, LinDa (2016) points out that the social construction of womanhood in Cambodia is subject to the instructions and guidelines stated in the Chbab Srey, which idealises proper Khmer women as respectful to their elders, obedient, patient, quiet, graceful, and possessing gentle and soft manners. This image of the Cambodian women is believed to still persist today: the ideal Khmer woman is to remain quiet, compliant and uneducated. Schoolgirls and female teachers in Cambodia are required to learn tenets of the Chbab Srey in schools and comply with the norms outlined in this code of conduct for women; they are instructed to respect their elders, become good wives and mothers, and more importantly, they must be obedient, submissive, and very careful and vigilant when speaking so as not to bring negative repercussions upon themselves (Anderson \& Grace 2018, pg. 1214). This view is also supported by Thavry who points out that the tenets of the Chbab Srey are deeply embedded in the lives of women in Cambodia: for generations, the women in her 
family unwaveringly adhere to the text and continue to embody the ideal Khmer women who is submissive, accepting and obedient, and does not talk back. Despite this, Thavry and many other Cambodian women, who represent the new generation of Khmer women, oppose these rigid guidelines and hope for their voices to be heard in the face of heavy criticism and backlash (Thavry 2017).

Similarly, in the novel, Ho first introduces Dara as a girl who is ignorant and oblivious to the difficult situation her family is in as she rides on an oxcart with her mother and brother, Sarun, to Nong Chan. She is expected to respect her mother and not to make her "any unhappier" (Ho 2010, p. 276). As they make their way to the Thai-Cambodian border to obtain provisions and tools to start a new life at their village after the fall of the Khmer Rouge regime, Dara constantly complains about her hunger and acts very childishly. She continues to badger her mother and brother, demanding food: "I want something now [.... But you just had breakfast [.... That was just a handful of cold rice" (Ho 2010, p. 276). She is reprimanded by her brother to remain quiet and not make any ruckus so as not to worry their mother; following his admonishments, she remains silent.

As discussed above, the first concept of identity fluidity by Hall emphasises that, at the enlightenment subject phase, the self, which is recognised as unified, stable and balanced, is linked to consciousness, awareness and agency where a person has a sense of control of his or her own actions, attitude and behaviour. At this phase of identity fluidity, Hall introduces the conception of the "inner core", or the centre of a person, that emerges during birth and will develop with the self. This "inner core" will remain the same throughout the individual's lifetime, however, as it helps him or her to have the ability to be completely aware and conscious of his or her own thinking, behaviours and decisions according to what they think is suitable.

In the novel, this acknowledgement of the self as unified, stable and balanced, and the sense of being in control of one's own actions, attitude and behaviour are reflected in Dara, who is implicitly aware of her "inner core" of being born a Cambodian girl. Initially, Dara is portrayed as a character that is ignorant, pampered and spoilt, one who depends heavily on her mother to look after her, and her mother both admonishes her to grow up and strokes her hair as if she were a little girl (Ho 2010, p. 290). After the war between the Vietnamese army and the Khmer Rouge regime, Dara, at 12 years old, is considered "still young", the fact of which she seems unaware (Ho 2010, p. 290), and, being a girl, she is not of much help. Most of the time, she is not included in discussions to obtain provisions and tools at the border but listens "quietly" to the discussions (Ho 2010, p. 296). When the time comes to collect the provisions and tools at the outskirts of Nong Chan, she is thus surprised that Sarun allows her to go with him (Ho 2010, p. 297).

Ho's portrayal of Dara reflects the very real experience of being a girl in traditional Cambodian society; one who, even at the age of 12 , is very much aware of the struggle and difficulties that she and her family have to endure during the horrifying and brutal rule of the Khmer Rouge. Dara is profoundly aware that she must remain silent and cannot openly show her sorrow and grief over the loss of her father, who was taken away and killed. As a Cambodian girl living in traditional society, her "inner core" leads her to believe that she is "not allowed to ask about him" (Ho 2010, p. 277) or even cry when she misses him. She thus remains quiet about the whole thing. In our view, this is a magnification of Hall's first stage of identity fluidity, the enlightenment subject, whereby the person's "inner core" is viewed as very "individualist", independent and self-reliant, capable of thinking, making decisions and acting where appropriate. Here, Dara is very aware of the hardship that they endure but, at the same time, as a traditional Cambodian girl, she follows instructions, is obedient, always remains silent and does not openly show her emotions and feelings. 
Hall also argues, however, that this unified, stable and balanced individual will be decentred when the person connects to society. This occurrence is manifested at the second stage of identity fluidity, namely the sociological subject phase, when identity is constructed through the person's association with other people who impose values, meanings and symbols onto the individual's daily life. In brief, as the person mingles, interacts and communicates with others, his or her identity will further be formed and influenced by other people and the culture of the world he or she lives in. Though Hall asserts that the person could be decentred through five major theoretical decentrings, namely language, social class, psychological unconsciousness, power relations and feminism, we argue here that Dara appears to reflect her decentring through transculture/ality. Dara experiences interactions and intermingling of communications with people in the refugee camp, namely Nea, a young woman who gives them food when they first arrived at the camp, Nea's grandfather, Grandpa Kem, Nea's cousin, Jantu, and her baby brother, as well as a boy called Chnay. This process, in turn, reflects transculture/ality and gradually affects the way she thinks, acts and behaves as she strengthens her "inner core" as a Cambodian young woman living in traditional Cambodian society.

Taking Dagnino's view on transculture/ality, individuals who experience intermingling of cultures have the capacity to dynamically select signs, values and beliefs from diverse cultures that best suit their contexts and circumstances. Here, the person experiencing transculture/ality is able to distinguish thoughts, signs, values and beliefs from others considered suitable and acceptable for them to connect to and link with. That said, in a more specific context, we find that Dara's acquaintance with Jantu implicitly reflects an emotional connection for Dara as the two develop a strong relationship and become close friends. Most of the time, Dara plays with Jantu and, at times, she listens and talks to Jantu as Jantu retells folktales that are mostly new to Dara, who "listens to her, spellbound, amid a small audience of other children" (Ho 2010, p. 302). Furthermore, Jantu can be identified as being the agent of change for Dara as Jantu uses "folktales to explain things to [Dara]" (Ho 2010, p. 302), imparting to Dara her insights of the war in Cambodia and how their country's leaders are not united in ideas and ideologies, fight among themselves and only bring misery to Cambodians.

At the same time, Dara is amazed at how good Jantu is at handcrafting as "she shaped things out of nothing. A knobby branch, in her deft hands, would be whittled into a whirling top" or how "she would weave strips of banana leaf into plump goldfish or angular frogs" (Ho 2010, p. 303). Here, Dara is not only in awe of Jantu's creativity, but Jantu also shows maturity, wisdom and sensibility at a very young age; this then shows her to be a huge influence on Dara as she repeatedly explains things to Dara and compels her to view things from different perspectives. As a result of her interaction, communication and relationship with Jantu, Dara's evolution of identity reflects that her perceptions of the values, meanings and symbols surrounding her have been indirectly influenced by Jantu. Capable of thinking and acting independently, Dara's unified, stable and fixed self is now decentred, and her identity starts to evolve enough for her to begin voicing her opinions and telling others what she considers to be the right thing to do, finally exhibiting freedom of mind and thought.

At this point in the novel, employing the concept of the enlightenment subject, we argue that Dara has formed an "inner core" that moulds her individual self. We can see, however, how her intermingling with a different type of female Cambodian, as embodied by Jantu with her own set of cultural beliefs, attitude and behaviour, has pushed Dara to form an identity that is transformed as she becomes "fully centred" and connects herself to society. This decentring of Dara, who initially appears to be ignorant, unaware of what is happening around her and perceived as unimportant by her brother, is further affected by the structural and institutional changes that occur when she is estranged from her family during the bombing and results in her identity becoming more "open-ended, variable and problematic" (Hall 2011, p. 598). 
In later scenes, as Dara makes her journey to find her family, she displays an identity that is distinct from the one she possessed at the beginning of the novel, before she is decentred. This is consistent with Dagnino's conception of transculture/ality that, as culture evolves through interactions and mixtures of communication between or among cultures, individuals have the agency to make their own cultural choices, act independently, and establish associations and layers of identity. In the scene below, after her many interactions and communications with Jantu, Dara is portrayed as feeling angry and trying to protect the toys Jantu made for her from being destroyed by a bully named Chnay:

\begin{abstract}
Chnay sauntered up and shoved his way through to us. "What've you got there?" He demanded. "Nothing," I said, trying to hide the toy behind me. Laughing, Chnay snatched it away from me. One of the dolls was ripped loose and dropped to the ground. As I bent over to retrieve it, Chnay pushed me aside. "Leave it," he said. [...] Dodging behind him, I tried to snatch the mobile back from him [...] I grabbed his hand, but he was taller than I, and much stronger [...] I squatted down beside the bits of dolls and tried to fit them together, but it was no use. (Ho 2010, pp. 305-306)
\end{abstract}

Here, Dara is portrayed as very brave, heroic and vocal when she fights with Chnay and protects her precious straw dolls. Dara confronts Chnay and deals with his bullying and outburst, and, at the same time, protects Jantu from being hurt by Chnay. Our findings, here, show that Dara's actions and behaviours clearly manifest her courage and boldness in speaking her mind. In our view, Dara here covertly reflects a person who has the agency to make her own decision, acts independently and establishes a multi-layered identity. This dovetails Hall's conception of the sociological subject, whereby the person who previously experiences a unified and stable identity is now said to be fragmented and comprise many contradictory identities as a result of his or her decentring, thereby changing further.

As discussed above, Hall argues that, as the process of identity formation becomes more flexible, fluid and difficult, the last stage of identity fluidity, namely the postmodern subject, manifests. This last concept is theorised as having no static, vital or lasting identity due to the ways we are represented or addressed within the cultural system that surrounds us as our identities are continuously being formed and modified. Rather, Hall stresses that, as the structures of meaning and the representation of cultures develop, we can only momentarily relate to any of this possible development of identities. In the novel, Dara becomes the postmodern subject as she continues to exhibit individual agency and her new identity with her own voice and opinions. As she searches for her family at the base camp of Kung Silor with Chnay, Dara is portrayed as being righteous and honest when she apologises to Kung Silor, bravely voicing her reasons for stealing the food and boldly asking Kung Silor if she can have the drumsticks that she has stolen:

\begin{abstract}
I swallowed hard. So this was the leader of the base camp. We couldn't have gotten into worse trouble if we had tried. 'Well? Answer me!' he thundered [...] 'I'm sorry, Mr. Kung Sir,' I managed to say. 'But we were hungry.' 'That doesn't mean you can steal my food,' Kung Silor said sternly. Well, how else would we have gotten it, I thought. To my horror, I found that I had spoken the thought aloud. [...] I looked at the drumsticks in Chnay's hand. A tickle of oil dripped off them. At that moment I felt I wanted a piece of chicken more badly than I had ever wanted anything. Impulsively, I took one of the drumsticks from Chnay, then turned to Kung Silor. 'Fine, I'll ask for it then. Can I have it, please?' I said.

(Ho 2010, p. 344)
\end{abstract}

We argue here, then, that though the essence of Dara as a Cambodian girl is still within her, which in turn corresponds with Thavry's (2017) perspective on the strong influence and power of the Chbab Srey on the Cambodian female, the essence is now shaped and altered through continuous interactions with Dara's cultural world "outside" and the identities it offers. We also argue that Ho's portrayal of Dara does not correspond with the stance by LinDa (2016) regarding the idealistic expectations of Cambodian women, who are expected to remain silent, to be submissive and obedient, and to not talk back to others. Ho, instead, portrays Dara as being righteous, truthful and fearless, traits that are indicative of her change in identity and are 
exemplified by her admitting her mistake of stealing the food from the kitchen and later being very determined to have them by asking Kung Silor if she can eat the stolen food.

Here, we find that Dara has experienced all three stages of identity fluidity, resulting in the demonstration of her own outspoken and assertive identity. As Hall asserts, after a person goes through the two first stages of identity fluidity, namely the enlightenment subject and the sociological subject, the person's identity will continue to develop due to the ways the person is either represented or addressed within the cultural system that surround him or her and in which identity is continuously moulded and created. From the beginning of the analyses, we have learned that Dara speaks her mind when she is tired and hungry and, more importantly, we have discovered that Dara never allows herself to be controlled by Sarun, Chnay or Kung Silor. As her identity develops and progresses, Dara becomes outspoken and speaks her mind when talking to the male characters in the novel as she sensibly and realistically challenges their views. As discussed previously, Dara does not show any patterns of behaviour manifesting her submissiveness towards Sarun or any other male figures in the novel, which supports an earlier view by Yuliana Tri Nirmayanti (2013) that Dara manages to unshackle herself from patriarchy through her strength and determination to voice her mind in order to achieve her desires, wants and needs. This means that our findings, with regards to Ho's portrayal of Dara, therefore do not support the pervasive Western view that the East Asian female identity is voiceless, submissive and hypersexual.

Further, Dara's portrayal manifests the reversal of roles as the head of the family, taking over Sarun's position: Dara is firm and adamant in her decision to go back to her village and voices her intention and decision to Sarun. Sarun, who is not pleased with Dara's decision, refuses to go back with her, causing a dispute. Dara succeeds, however, in ensuring Sarun that her decision is right and well-founded by saying, "What about going home? What about trying to live in peace, when there is a war going on? Doesn't that take courage, too?"' (Ho 2010, p. 387).

At this point, we argue that Dara is beginning to display her firmness and have the agency to make her own decision again when she does not give in to her brother's demand of not going home and starting a new life. We maintain that Dara's outspokenness and resolve also demonstrate the evolution of Dara's identity. More importantly, Dara's portrayal can be identified as an independent young woman who matures into an adult through her experiences and thoughts; she understands what is happening around her and the difficulties that she has endured, and defines herself not only as a survivor of life's hurdles but also as a leader. Our findings show that, despite winning in her own right, voicing her own perspectives and not submitting to patriarchal domination, the evolution of Dara's identity can also be attributed to the three stages of identity fluidity, namely the enlightenment subject, the sociological subject and the postmodern subject. More specifically, as Dara experiences the second stage of identity fluidity that is the sociological subject, she becomes decentred through transculture/ality and further alters her identity as she enters the third stage of identity fluidity, namely the postmodern subject.

\section{CONCLUSION}

Our foregoing analyses of Ho's portrayal of Dara's practice of culture in Cambodian society explored the Western notion that the East Asian female identity is submissive, voiceless and hypersexual. Because, as Hall asserts, identity can dynamically and continually form and transform after the decentring of the individual, this decentring through cultural intermingling, or transculture/ality as conceptualised by Dagnino, can also have the same effect. Our analyses have revealed that Dara becomes decentred through her intermingling of cultures with the 
many individuals that she meets: she finds herself empowered, has her own voice and ultimately succeeds in challenging patriarchy and breaking the social norm of the ideal Khmer woman in a traditional Cambodian society. This transformation can all be attributed to the three stages of identity fluidity propounded by Hall. Strikingly, there is no evidence to suggest that Dara is hypersexual in the novel. It is therefore safe to conclude that, through the literary lens and application of these concepts of identity fluidity and transculture/ality, our exploration of the Western view of the East Asian female identity perceived as submissive, voiceless and hypersexual shows a renegotiation of a fluid and transcultural female Cambodian self.

Our study is of course limited to Ho's portrayal of Dara in The Clay Marble and to the conceptual frameworks of identity fluidity and transculture/ality. Future research must be undertaken by comparing other characters in this novel with other literary texts used in the Malaysian secondary school syllabus such as Ho's Sing to the Dawn (1975). Additionally, further research can also be conducted by applying Hall's concept of identity fluidity with the concept of the third space by Homi Bhabha in order to examine how female characters in Ho's novels reconstruct their identities based on transculture/ality.

\section{ACKNOWLEDGEMENTS}

This paper was supported by the Research Fund provided by Universiti Putra Malaysia Geran Putra Siswazah GP-IPS/2018/9653400 for academic and postgraduate researchers. The authors would also like to thank Enago (www.enago.com) for the English language review.

\section{REFERENCES}

Al-Karawi, S. T. \& Bahar, I. B. (2013). Negotiating liminal identities in Mohja Kahf's The girl in the tangerine scarf. International Journal of Applied Linguistics and Literature, 2(2), 101-106.

Al-Karawi, S. T. \& Bahar, I. B. (2014). Negotiating the veil and identity in Leila Aboulela's Minaret. GEMA Online ${ }^{\circledR}$ Journal of Language Studies, 14(3), 255-268.

Almutairi, A. S., Hashim, R. S. \& Mydin, R. M. (2017). Grafting eco-diasporic identity in Randa Abdel-Fattah's selected novels. GEMA Online $®$ Journal of Language Studies, 17(4), 179-190.

Anderson, E. \& Grace, K. (2018). From schoolgirls to 'virtuous Khmer women': Interrogating Chbab Srey and gender in Cambodian education policy. Studies in Social Justice, 12(2), 215-234.

Bahar, I. B. (2019). Literature relived: $21^{\text {st }}$ century literary research paradigms amidst the 4IR. Paper presented at the 2nd Annual International Conference on Language and Literature (AICLL) (pp. 60-73). Medan, Indonesia: Islamic University of North Sumatra, July.

Bahar, I. B., Kamarudin, K., Maming, P. H. \& Razak, F. A. (2019). An endless identity dilemma: The liminal Westernised Muslim Malays in The enemy in the blanket by Anthony Burgess. International Journal of Applied Linguistics and English Literature, 8(1), 212-223.

Chang, H. (2017). The body and female identity in Eithne Strong's Flesh: The greatest sin. 3L: Language, Linguistics and Literature ${ }^{\circledR}$ The Southeast Asian Journal of Language Studies, 23(4), 157-169.

Chin, C. (2019). New SPM English Literature syllabus. Star Online. Retrieved July 11, 2019 from https://www.thestar.com.my/news/nation/2019/06/23/new-spm-english-lit-syllabus/

Christiyanto, Y. \& Widyahening, E. T. (2016). A discourse analysis of speech acts in Minfong Ho's novel entitled The clay marble. Karya Ilmiah Mahasiswa Progdi Pendidikan Bahasa Inggris, 2(2), 1-15.

Chua, G. C., Bahar, I. B. \& Noor, R. (2016). Honour killing as engendered violence against women in Amit Majmudar's Partitions (2011). 3L: Language, Linguistics and Literature ${ }^{\circledR}$ The Southeast Asian Journal of English Language Studies, 22(1), 221-233.

Dagnino, A. (2015). Transcultural writers and novels in the age of global mobility. Indiana: Purdue University Press.

Dodhy, S., Kaur, H., Yahya, W. R. W. \& Bahar, I. B. (2017). The role of secure base and safe haven: A means of reconstructing the broken-self in Yvonne Vera's Under the tongue. Pertanika Journal of Social Sciences \& Humanities, 25(4), 1821-1832.

Hall, S. (2011). The question of cultural identity. In Hall, S., Held, S., Hubert, D. \& Thompson, K. (Eds.). Modernity: An introduction to modern societies (pp. 595-634). Malden, MA: Blackwell.

Ho, M. (2010). The Minfong Ho collection. Singapore: Marshall Cavendish Editions.

Jafni, N. F. S. A. \& Bahar, I. B. (2014). Feminine mystique and the patriarchal world in Tillie Olsen's I stand here 
ironing. Journal of Language and Communication, 1(2), 249-260.

Krishnamoorthy, R. \& Krishnamurthy, B. (2016). Rebirth of self and identity: An analysis of Meena Alexander's Manhattan music. 3 L: Language, Linguistics and Literature ${ }^{\circledR}$ The Southeast Asian Journal of Language Studies, 22(2), 81-90.

LinDa, S. (2016). Gendered modernity in Cambodia: The rise of women in the music industry. Khmer Scholar. Retrieved December 12, 2018 from http://khmerscholar.com/gendered-modernity-in-cambodia-the-riseof-women-in-the-music-industry/

"Minfong Ho". (n.d.). The authors guild. Retrieved November 22, 2017 from http://minfong.ag-sites.net//bio.htm Moosavinia, S. R. \& Yousefi, T. B. (2018). New norms of gender and emergence of identity crisis in Margaret Atwood's The handmaid's tale. 3L: Language, Linguistics and Literature ${ }^{\circledR}$ The Southeast Asian Journal of Language Studies, 24(1), 162-174.

Nirmayanti, Y. T. (2013). Young ordinary women as strugglers, leaders and conflict survivors in Minfong Ho's novels. Master's thesis, Sanata Dharma University, Yogyakarta, Indonesia.

Rama, A. (2018). Bringing women to the front of Cambodia's art scene. Khmer Times. Retrieved December 12, 2018 from https://www.khmertimeskh.com/112291/bringing-women-to-the-front-of-cambodias-artscene/.

Razak, F. A., Bahar, I. B. \& Talif, R. (2016). Emerging patterns of bangsa Malaysia in Anthony Burgess' Time for a tiger. International Journal of Applied Linguistics and English Literature, 5(1), 265-271.

Salih, E.G., Kaur, H., Bahar, I. B. \& Hassan, M. F. (2018). Rape talks louder than guns: feminising men via wartime rape in Judith Thompson's Palace of the end. Pertanika Journal of Social Sciences \& Humanities, 26(1), 285-298.

Sheeley, A. M. (2012). Learning for Cambodian women: Exploration through narrative identity and imagination. $\mathrm{PhD}$ thesis, The University of San Francisco, San Francisco, California.

Thavry, T. (2017). A proper woman: The story of one woman's struggle to live her dreams. Middletown DE: Thavry Thon.

Wiggins, J. L. (2006). Minfong Ho: Politics in prose. Journal of Children's Literature, 32(2), 52-59.

Yusof, N. M., Hashim, R. S. \& Mydin, R. M. (2012). Remembering home: Palestine from a distance. $3 L$ : Language, Linguistics and Literature® The Southeast Asian Journal of Language Studies, 18(2), 95 103.

Zabihzadeh, S., Hashim, R. S. \& Chua, G. C. (2015). Domestic violence against women in Atiq Rahimi's The patience stone. GEMA Online ${ }^{\circledR}$ Journal of Language Studies, 15(3), 51-66. 